\title{
Mechanical properties of leaf sheath date palm fibre biomass waste reinforced polycaprolactone (PCL) biocomposites
}

Hom Dhakal $^{\mathrm{a}, *}$, Alain Bourmaud ${ }^{\mathrm{b}}$, Francoise Berzin ${ }^{\mathrm{d}}$, Fahad Almansour ${ }^{\mathrm{a}}$, Zhongyi Zhang $^{\mathrm{a}}$, Darshil U. Shah ${ }^{\mathrm{c}}$, Johnny Beaugrand ${ }^{\mathrm{d}, \mathrm{e}}$

${ }^{a}$ Advanced Materials and Manufacturing (AMM) Research Group, School of Engineering, University of Portsmouth, Portsmouth, Hampshire PO1 3DJ, United Kingdom

${ }^{\text {b }}$ Université de Bretagne Sud, IRDL, UMR CNRS 6027, Lorient, France

${ }^{\mathrm{c}}$ Centre for Natural Material Innovation, Dept. of Architecture, University of Cambridge, Cambridge CB2 1PX, United Kingdom

${ }^{\mathrm{d}}$ Fractionnement des Agro Ressources et Environnement (FARE), URCA INRA, 2 esplanade Roland Garros, F-51100 Reims, France

${ }^{\mathrm{e}}$ Biopolymères Interactions Assemblages (BIA), INRA, rue de la Géraudière, F44316 Nantes, France

ABSTRACT

Date palm fibres are one of the most available natural fibres in North Africa and the Middle East. A significant amount of date palm fibres biomass is wasted annually and only limited amounts are used in low value products. In this study, tensile and low-velocity impact response of biodegradable lignocellulosic biomass reinforced polycaprolactone (PCL) biocomposites are reported. Two different types of laminates reinforced with date palm fibre obtained from agriculture waste were manufactured by an extrusion process. The influence of processing parameters, such as screw rotation speed on the tensile and low velocity impact damage characteristics have been investigated. The tensile strength increased for neat PCL from $19 \mathrm{MPa}$ to 25 MPa with 28 wt.\% reinforcement of date palm fibres. Similarly, the tensile modulus for neat PCL was increased from $140 \mathrm{MPa}$ to $282 \mathrm{MPa}$ upon reinforcement. The screw rotation speed showed a moderate effect on palm fibre morphologies, and slight effect on tensile properties of the biocomposites. Specimens with lower incident energy of $25 \mathrm{~J}$ achieved better impact resistance compared to that of $50 \mathrm{~J}$. The impact damage of biocomposites analysed through electron microscopy on the fractured surface showed various modes of damage. The biocomposites developed in this work can be used as an economically and environmentally attractive alternative materials for lightweight applications in automotive and marine sectors. 
* Corresponding author. Tel: + 44 (0) 239284 2582; fax: + 44 (0) 2392842351.

E-mail: hom.dhakal@port.ac.uk

\section{Introduction}

The total costs of production (energy/power) and maintenance of conventional (synthetic) fiber-reinforced polymer (FRP) composites such as glass and carbon FRP composites are relatively higher when compared with that of natural FRP composites such as date palm, hemp or flax biocomposites. In addition, the problems of unstable interfacial adhesion of the fiber and matrix often results in fiber-pull out, and matrix de-bonding as well as inter-ply delamination are more rampant with synthetic FRP composites than the natural counterparts. Importantly, date palm fiber/polycaprolactone biocomposites are completely biodegradable, renewable, sustainable and recyclable materials, unlike the synthetic FRP composites, hence. Hence, date palm/PCL have a very low level of toxicity which makes them environmentally friendly and relatively safe for human health during processing and life cycle. Moreover, their light weight leads to attractive specific properties such as high strength-toweight ratios in comparison to their non-renewable, high energy-intensive reinforcing synthetic counterparts such as glass and carbon fibres. These positive attributes of natural fibre reinforcements are particularly attractive to the automotive original equipment manufacturers (OEMs) as they are facing the challenge of producing light parts at low cost. In this context, biocomposites reinforced with low density fibres such as date palm and biodegradable matrix such as polycaprolactone (PCL) can offer alternative solutions to the petroleum based polymers and non-renewable synthetic reinforcements (Faruk et al., 2012; Paul et al., 2015).

There are several research works reported in the past focusing on the development and applications of natural plant fibre reinforced thermoplastic and thermoset 
59 composites in automotive, marine, and construction industries (Dhakal et al., 2007;

60 Mohanty et al., 2000). Due to their main constituents being cellulose, hemicellulose

61 and lignin, plant fibres are also known as lignocellulosic fibres. Investigations on

62 mechanical properties of these fibres suggest that the specific tensile stiffness- of

63 some commonly used natural fibres such as hemp, flax and sisal are comparable to

64 those exhibited by synthetic reinforcements (Joshi et al., 2004; Summerscales et al.,

65 2010). However, these reported works also point out that despite their attractive

66 mechanical and environmental attributes, these plant fibre reinforcements suffer with

67 non-uniform properties leading to variable mechanical performances, poor fibre-

68 matrix compatibility, and concerns relating to long-term durability (Charlet et al.,

69 2007). Moreover, a plant fibre bundle for example consists of several cells composed

70 of cellulose, hemicellulose and lignin. The ratio of these constituents vary from one

71 fibre to the other. This structural complexity and dimensional inhomogeneity often

72 contribute to varied and distinct properties of plant fibres which influence the final

73 properties of the composites (Stamboulis et al., 2001).

74 In the last several years, significant interest has emerged in the development of 75 composite materials from waste precursors. This new approach will not only tackle 76 waste disposal problems, but also provide an adequate route for resource utilisation, 77 hence supporting the sustainable development agenda by balancing social, 78 environmental and economic considerations. The utilisation of waste date palm fibres 79 in composite reinforcements can be a step forward in contributing resource 80 maximisation. Currently, the bulk of date palm fibres are used in low value products.

81 Therefore, the use of agricultural residues such as date palm fibres through sensible 82 and innovative ways of utilisation is of potential interest to researchers and industry 83 (Bledzki and Gassan, 1999; Nasser et al., 2016). 

dactylifera L.), a member of the palm tree family (Arecaceae), is one of the most cultivated palms in North Africa and the Middle East, including in countries such as

87 Tunisia, Algeria, United Arab Emirates, Saudi Arabia, Egypt, Iraq and Iran. After date 88 fruit harvesting, date palm rachis waste is accumulated on agricultural land every year 89 in these countries (Chao and Krueger, 2007). The major constituent of date palm fibre 90 is cellulose (46\%), hemicelluloses (18\%), lignin (20\%) and ash (10.54\%). Date palm 91 trees produce a large quantity of agriculture waste. For example, each tree produces $9220 \mathrm{~kg}$ of dry leaves annually. This waste is burned in the farms, causing serious 93 environmental pollution as well as death of important soil microorganisms (Alawar et 94 al., 2009).

The part of the date palm tree which is often used as fibres is the sheath. The sheath is the part of the tree which surrounds the trunk of the plant attached to its

97 lateral edges near the top of the trunk as shown in Fig. 1. Sheath is also known under 98 the name of leaf and is often torn lose when pruning the leaves. Seeking to use them 99 as useful material resources instead would bring economic growth. If these 100 agricultural residues are utilised in building materials (Alsaeed et al., 2013) or for 101 example as composite reinforcements, a tremendous value-added by-product can be 102 realised. The residue generated from the palm tree is currently used in a variety of 103 applications such as particle board, low and medium density fibre board, pulp and 104 paper. But these wastes have not been fully-utilised as an economic alternative 105 (Abdelaziz et al., 2016; Nasser et al., 2016).

106 Despite several benefits of date palm fibres outlined, to the authors' best 107 knowledge, there are limited reported studying biocomposites developed from waste 108 date palm fibre residue and investigating their low velocity impact behaviour. The 
109 main objective of this study is to evaluate the suitability of date palm fibre as

110 alternative reinforcements in composite materials. The reinforcing effects of date

111 palm fibres obtained from palm leaf sheath on the resulting extruded and injected

112 PCL biocomposites are investigated by categorising the important parameters

113 influencing on the low velocity impact and tensile properties. In addition, the

114 influence of screw rotation speed on palm fibre defibrillation (Alawar et al., 2009)

115 and flow conditions along the twin screw extruder (TSE) are analysed in order to

116 calculate the specific mechanical energy (SME) provided to the fibres. Furthermore,

117 the influence of extruder screw rotation speed and palm fibre reinforcements on the

118 tensile and impact properties including load bearing capability, energy absorption,

119 impact damage characteristics from the falling weight impact are analysed and 120 discussed.

121 2. Materials and methods

$122 \quad 2.1 \quad$ Materials

123 Date palm fibres (Phoenix dactylifera L.) were obtained from a farm in Al-Ahsa, 124 located in the Eastern Province of Saudi Arabia, as decametric bundles (Fig 1, a-b). 125 Prior to Twin Screw Extrusion (TSE), the palm bundles were chopped into a master 126 batch with an average length of approximately $1 \mathrm{~cm}$ (Fig 1, c, average length Lw 127 equal to $10400 \mu \mathrm{m}$ ) with a plant shredder equipped with a $2 \mathrm{~mm}$ sieve (Retsch, Haan 128 Germany). The chopped fibre bundles were then stored at $20^{\circ} \mathrm{C} \mathrm{C}$ and $50 \%$ relative 129 humidity in a climatic chamber prior TSE. The SEM images of date palm fibre are 130 depicted in Fig. 2.

131 The box plot give the upper Quartil (Q1), the quartil 3 (Q3), the median length 132 (Lmed) and the mean Length (Lw) with values incrusted in the graphic. 
Fig. 1.

134 The thermoplastic matrix used was polycaprolactone (PCL) of low melting 135 temperature $\left(60^{\circ} \mathrm{C}\right)$. PCL (Capa $\odot$ 6800) was provided by Perstorp, United Kingdom, 136 having a molecular weight of $80,000 \mathrm{~g} / \mathrm{mol}$ and a melt flow index (MFI) of $3 \mathrm{~g} / 10$ $137 \min \left(160{ }^{\circ} \mathrm{C}, 2.16 \mathrm{~kg}\right)$.

138 The longitudinal morphology of the date palm fibre examined by SEM is shown in 139 Fig. 2. The tensile strength and stiffness of the composites is presented in the form of 140 an Ashby's materials selection chart in Fig. 3 (Shah, 2014), comparing the 141 performance with other natural bast fibre composites. The comparative physical and 142 mechanical properties of date palm fibre with other commonly used bast fibre are 143 presented in Table 1 (Dhakal et al., 2007; Mohanty et al., 2000; Pickering et al., 144 2016).

Table 1

Fig. 2.

Fig. 3.

\subsection{Composite manufacturing}

The compounds were prepared using chopped palm fibre (Fig 1, c) mixed with a PCL matrix at a concentration of 20 wt. \% with a laboratory-scale twin-screw corotating extruder TSE ZSE 27 MAXX (Leistritz, Germany). Its main characteristics are as follows: centerline distance $22.7 \mathrm{~mm}$, screw diameter $28.3 \mathrm{~mm}$, length/diameter ratio 36. In addition to screw conveying elements, it comprises a left-handed element in zone 3 to ensure the melting of the polymer matrix and two mixing blocks in zones 6 and 8, to disperse the fibres. The first one is constituted of a block of kneading discs, staggered at $90^{\circ}$, and the second one of a block of kneading discs, but staggered at $-60^{\circ}$. The matrix is introduced in zone 1 , melted in the left-handed element (zone 3 ) and the fibres are then added in zone 4. During all experiments, the barrel temperature 

and $400 \mathrm{rpm}$ ) was varied.

161 In order to estimate values of parameters that cannot be measured experimentally 162 during the compounding process, we have used the flow simulation software 163 Ludovic $($ ) dedicated to twin screw extrusion (Vergnes et al., 1998). Specifically, 164 Ludovic $($ ) was used to calculate the specific mechanical energy (SME) transmitted to 165 the composite all along the extruder.

166 The SME is calculated from equation (1):

$$
E M S=\frac{1}{Q} \int_{0}^{x} \eta(x) \dot{\gamma}^{2}(x) V(x) d x
$$

where, $\mathrm{Q}$ is the mass flow rate, $\eta$ the viscosity, $\dot{\gamma}$ the shear rate and $\mathrm{V}$ the design volume considered. Fig. 4 represents the change in SME along the screws for two 170 different screw speeds.

Fig. 4.

172 After extrusion, the composite strands were cooled down at room temperature and 173 the compounds were granulated (approx. $8 \mathrm{~mm}$ in length).

174 Standard dumbbell specimens were injected using a bench scale DSM Xplore 175 (Geleen, The Netherlands) according to the procedure of -Haag et al. (2017). Ten 176 specimens were tested for each condition.

177 To analyse the morphometry of the compounded samples, the PCL dissolution was 178 done as described by Beaugrand and Berzin (2013) (Fig 1, d-e). Then, the 179 morphometric description was done according to the method of Di Giuseppe et al. 180 (2016) using a 2D high-resolution image scanning. 
181 Laminates of $200 \times 200 \mathrm{~mm}$ length, $5 \mathrm{~mm}$ thick were manufactured by press 182 moulding as described in Ismail et al. (2016). The press is a two columns automatic 183 laboratory hydraulic press (Carver, Wabash, IN) equipped with heating platens.

\subsection{Tensile testing}

185 Tensile testing was carried out on a universal testing machine (Testwell, Saint 186 Ouen, France) equipped with a mechanical extensometer. The tensile testing was 187 carried out according to the ISO 291:2008 standard. The loading rate used was 1 $188 \mathrm{~mm} / \mathrm{min}$.

\subsection{Low velocity impact test}

190 Zwick/Roell HIT230F instrumented falling weight drop impactor was used for 191 instrumented falling weight impact testing. The composite specimens were cut from 192 the Palm/PCL composite laminates using a band saw to a square dimension of $60 \times 60$ $193 \mathrm{~mm}$ with $5.7 \mathrm{~mm}$ thickness at two energy levels: 25J (with an impact velocity 1.47 $194 \mathrm{~m} / \mathrm{s}$ ) and 50J (with an impact velocity $2.08 \mathrm{~m} / \mathrm{s}$ ) at room temperature. The diameter of 195 the hemispherical steel tup was $19.8 \mathrm{~mm}$. Impact parameters such as peak force, 196 absorbed energy, deformation were continuously recorded for every specimen at each 197 impact event performed using a load cell and a strain-gauge striker fitted on the 198 system. A catcher mechanism was activated to avoid the multiple damage on the 199 specimens. A schematic of drop weight impact mass, hemispherical impact tup and 200 clamping systems are shown in Fig. 5. Similar impact test parameters were used to 201 impact hemp/PCL composites in order to compare the impact damage behaviour of 202 palm/PCL biocomposites. 
Impact failure surfaces of different biocomposites were pre-coated with a thin gold

206 film and observed in a Phillips XL30CP scanning electron microscope (SEM) at 15

$207 \mathrm{kV}$ acceleration voltages.

\section{Results and discussion}

\subsection{Tensile properties (strength and modulus)}

The tensile properties of different reinforcement configurations are summarised in

211 Table 2. The tensile results show that there is a clear influence of date palm 212 reinforcement on the tensile strength, modulus and strain at break. There was 213 improvement in tensile strength for example from $19 \mathrm{MPa}$ for neat PCL to $24 \mathrm{MPa}$ for 214 20wt.\% Palm/PCL. Moreover, there is a significant improvement in tensile modulus 215 from $140 \mathrm{MPa}$ for neat PCL to $284 \mathrm{MPa}$ for $20 \mathrm{wt} . \%$ Palm/PCL biocomposites. This 216 increase in strength and modulus is attributed to the fibre reinforcement effects as 217 well as employed extruder parameters. The elongation at break is significantly higher 218 for neat PCL compared to palm fibre/PCL biocomposites and this is expected as the 219 PCL is a ductile matrix and the strain at break is matrix dominated property in this 220 case. The tensile strength properties obtained in this study are in close agreement with 221 the reported work by Mahdavi et al. (2010) where they have presented tensile strength 222 of date palm fibre reinforced polyethylene composites. In comparison, the results 223 obtained (24 MPa) in this work were found to be higher than their reported results 224 using rachis 20 wt.\% from date palm as reinforcement in polyethylene matrix. In our 225 case, the use of a PCL matrix, having more interfacial compatibility with plant 226 components, is a significant advantage 

during compounding. There is a slight variation in terms of measured tensile Young's modulus and tensile strength (Table 2). The rotation speed also seems to affect the

230 palm fibre morphologies (Fig. 1) with Lw of 985 and 765 when extruded at 100 and $231400 \mathrm{rpm}$, respectively. Because some extrusion parameters, including screw speed, are 232 known to impact lignocellulosic fibre morphologies, one could have expected 233 pronounced differences in composite tensile properties between those two. Indeed, the 234 feed rate, (Beaugrand and Berzin, 2013; Berzin et al., 2014), the recycling (Bourmaud 235 et al., 2016), could impact on the fibre morphology which in turn impacts mechanical 236 properties (Beaugrand and Berzin, 2013) or processing alteration (Ismail et al., 2016). 237 Because screw rotation speed is known to modulate the specific mechanical energy 238 (SME), the commercial software Ludovic $@$ was used to calculate SME transmitted to 239 the composite all along the extruder. This commercialised software is based on a one240 dimensional (1D) approach. It allows the calculation of the main thermomechanical 241 parameters of the process, from the hopper to the die exit, including solid conveying, 242 melting and melt conveying. It has been shown that the fibre fragmentation depended 243 on the SME provided to the fibres (Beaugrand and Berzin, 2013; Berzin et al., 2014, 244 2017). As an example, Fig. 4 shows the evolution along the screw profile of the global 245 SME that we can compare to experimental values calculated from the measured 246 torque. It is observed that the SME increases in the left handed element, in the blocks 247 of kneading discs and in the filled section prior to the die. Marked differences 248 between $100 \mathrm{rpm}$ and $400 \mathrm{rpm}$ are then obtained.

249 However, there is no pronounced difference in tensile properties between samples 250 made at 100 and $400 \mathrm{rpm}$. A close look at the length population distribution (Fig. 1 251 box plots) sheds a new light. Indeed, the overall length distribution is first quite 
253 illustrates that only one average or median value is generally not enough to describe

254 lignocellulosic fibre morphology (Di Giuseppe et al., 2016; Hamdi et al., 2015)

\section{Table 2}

The materials selection chart in Fig. 3 enables comparison of the tensile strength and stiffness of the injection moulded date palm fibre composites with other bast fibre composites. We find that the date palm fibre composites have comparable strength to other injection moulded bast fibre composites and neat resins, however the stiffness is much lower. This is explained by the substantially lower stiffness of date palm fibres in comparison to bast fibres like flax, jute and hemp (Table 1). Anecdotal observations from tensile properties of compression moulded, unidirectional date palm fibre composites reveal substantially lower strength and stiffness in comparison to compression moulded, unidirectional bast fibre composites. Rather the former have similar performance to compression moulded, non-woven (2D random fibre orientation) bast fibre composites.

\subsection{Low velocity impact characteristics}

\subsubsection{Force-displacement analysis}

To evaluate impact damage characteristics, criteria such as maximum force, energy absorbed, force displacement and visual observation were used. Force versus displacement traces obtained from the low velocity impact testing for palm fibre/PCL specimens impacted at two different energy levels are depicted in Fig. 6 (a). Contact force is generally defined as reaction force exerted by the specimen to the impactor. As shown in Fig. 6 (a), the maximum contact force has slightly increased with the increase in incident energy level. From these curves, it can be seen that the increase in 
energy level from 25 to $50 \mathrm{~J}$ has not caused a major difference in peak load. The maximum load reached for $25 \mathrm{~J}$ impacted specimen is approximately $2425 \mathrm{~N}$, with a displacement of approximately $8 \mathrm{~mm}$ at peak force.

The peak force for specimens impacted at energy level of $50 \mathrm{~J}$ has been recorded at approximately $2535 \mathrm{~N}$ and unlike $25 \mathrm{~J}$ energy level, the curve for this specimens has reached zero which is an indication of samples fully perforated.

Fig. $6(\mathrm{a}-\mathrm{c})$.

\subsubsection{Force-time comparisons}

The contact force-time traces corresponding to impact event for each specimen subjected to incident energy of 25 and $50 \mathrm{~J}$ are illustrated in Fig. 6 (b). The time taken to complete the impact event is different for each specimen. It is evident that at the lower energy level, the palm fibre/PCL biocomposite shows more impact resistance, thereby taking longer time to complete the impact event compared to higher energy impacted samples.

\subsubsection{Energy-time comparisons}

The impact strength of composites is defined by its ability to withstand fracture or the amount of energy required to initiate damage. Absorbed energy versus time plots for different specimens are shown in Fig. 6 (c). It is evident from the figure that the absorbed impact energy for both samples are almost identical. However, the visual inspection of impacted samples at $50 \mathrm{~J}$ incident energy level shows a big difference than that of incident energy of $25 \mathrm{~J}$. On the samples being impacted at the incident energy of $50 \mathrm{~J}$, the material was fully penetrated. This is due to the high incident energy allowing the impactor to penetrate. 
Fig. 7 (a) -(c) show the impact parameters (peak load and absorbed energy) of 300 hemp/PLC biocomposites used to compare the results obtained for palm/PCL 301 biocomposite specimens. It is evidenced from the Figure 7 (a) that hemp/PCL 302 specimens have lower peak load and displacement compared to palm/PCL specimens. 303 Similarly, the hemp/PCL specimens absorbed low impact energy (lower dissipated 304 energy) as depicted in Fig. 7 (c) compared to palm/PCL specimens. This results are 305 evidences that the palm/PCL biocomposites can be promising sustainable materials 306 when improved impact performance is critical.

\subsection{Impact damage characterisation}

309 The visual inspection of palm/PCL impacted at $25 \mathrm{~J}$ (Fig. 8) clearly shows that the specimens have not been fully penetrated but there is a clear indication of radial

311 cracking and perforation.

Fig. 8.

313 For samples impacted at higher energy level $(50 \mathrm{~J})$, there is evidence of matrix 314 cracking around the impacted hole, as energy was not distributed throughout the 315 specimen and it was penetrated through (Fig. 9). The higher velocity of impact event 316 allowed the impactor to puncture the samples. The damage area and size for this 317 sample was larger than the samples impacted at $25 \mathrm{~J}$ incident impact energy.

Fig. 9.

319 The rear faces of all specimens show similar damage propagation. However, larger 320 penetration hole and fibre shear out are visible for specimen impacted at higher 321 energy level (Fig. 9). The extent of damage is larger for samples with $50 \mathrm{~J}$ incident 322 energy level. 
324 Representative SEM images of impact fractured surfaces of these two samples are 325 shown in Figs. 10 and 11. From SEM images of the impact at incident energy level of $32625 \mathrm{~J}$ specimens (Fig. 10), it is observed that matrix bending and fibre delamination are 327 apparent. The SEM images suggest that there was poor fibre matrix interface leading 328 to better energy dissipation which has resulted in better impact resistance behaviour 329 but lower tensile strength and modulus. For higher incident energy level, the fractured 330 surfaces reveal that the fibres are exposed, unravelled and also pulled out. The PCL is 331 a ductile matrix while the SEM images (Fig. 11, b) show no residue of matrix on the 332 pulled out fibre which is an indication of poor fibre-matrix adhesion. This behaviour 333 normally leads to better toughness properties and lower tensile strength and modulus. 334 It can be observed from SEM images that there are some gaps between matrix and 335 fibre which is an indication of insufficient consolidation of fibres during the 336 manufacturing and caused by incompatibility between fibre and the matrix.

\section{4. Conclusions}

340 Using date palm fibres from waste as reinforcements in PCL based biocomposites 341 was found to be effective approach for obtaining an acceptable tensile and impact 342 resistance behaviour. It was evident from the experimental results that samples with 343 higher extrusion screw speed have average fibre length shorter than those extruded 344 with lower screw speed (400 vs $100 \mathrm{rpm}$ ) but the specimen composites do not 345 withstand more than a slightly higher tensile stress than that of $100 \mathrm{rpm}$, arguably due to a very disperse fibre morphology population. However, the tensile test results 

showed that date palm fibre reinforced PCL biocomposite laminates have acceptable tensile strength and modulus with respect to currently available literature data.

With regards to low velocity impact resistance behaviour, both samples showed similar behaviour apart from $25 \mathrm{~J}$ incident energy level showing resistance to penetration in comparison to $50 \mathrm{~J}$ of incident energy.

Investigating the suitability of date palm fibres biomass waste as reinforcement in light weight composite materials shows a tremendous opportunity of utilising this material to develop a low cost composites. Hence, it can contribute to reduce the overall environmental damage, better way of utilisation of resources and reduction of total cost for the manufacturing of composites, which is a clear benefit in many applications. Furthermore, the findings of this study has a great potential of benefitting composite manufacturing industries, research institutes and academia, as they work or study/research to improve the properties of natural fiber-reinforced biocomposite materials.

\section{Acknowledgements}

Johnny Beaugrand acknowledges the financial support from the MATRICE 'CPER France-Champagne-Ardenne' program and Justine Padovani (INRA) is acknowledged for her critical discussion. The authors thank Francois Gaudard from INRA for his technical assistance in polymer extraction and the authors also express their thanks to Miguel Pernes and Alain Lemaitre (both from INRA) for their support during twin screw extrusion. Hom Dhakal would like to thank Mr Raphael Teles for his support in carrying out impact testing and SEM during his placement period here at the APC Research Group, UoP.

Funding: This research did not receive any specific grant from funding agencies in the public, commercial, or not-for-profit sectors. 
Abdelaziz, S., Guessasma, S., Bouaziz, A., Hamzaoui, R., Beaugrand, J., Souid, A.A., 2016. Date palm spikelet in mortar: Testing and modelling to reveal the mechanical performance. Constr. Build. Mater. 124, 228-236.

Alawar, A., Hamed, A.M., Al-Kaabi, K., 2009. Characterization of treated date palm tree fiber as composite reinforcement. Compos. Part B Eng. 40, 601-606.

Alsaeed, T., Yousif, B.F., Ku, H., 2013. The potential of using date palm fibres as reinforcement for polymeric composites. Mater. Des. 43, 177-184.

Beaugrand, J., Berzin, F., 2013. Lignocellulosic fiber reinforced composites: Influence of compounding conditions on defibrization and mechanical properties. J. Appl. Polym. Sci. 128, 1227-1238.

Berzin, F., Vergnes, B., Beaugrand, J., 2014. Evolution of lignocellulosic fibre lengths along the screw profile during twin screw compounding with polycaprolactone. Compos. Part A Appl. Sci. Manuf. 59, 30-36.

Berzin, F., Beaugrand, J., Dobosz, S., Budtova, T., Vergnes, B., 2017. Lignocellulosic fiber breakage in a molten polymer. Part 3. Modelling of the dimensional evolution of the fibers during compounding by twin screw extrusion, Compos. Part A, 101, 422-431.

Bledzki, A.K., Gassan, J., 1999. Composites reinforced with cellulose based fibres. Prog. Polym. Sci. 24, 221-274.

Bourmaud, A., Åkesson, D., Beaugrand, J., Le Duigou, A., Skrifvars, M., Baley, C., 2016. Recycling of L-Poly-(lactide)-Poly-(butylene-succinate)-flax biocomposite. Polym. Degrad. Stab. 128, 77-88.

Chao, C.C.T., Krueger, R.R., 2007. The date palm (Phoenix dactylifera L.): Overview of biology, uses, and cultivation. HortScience 42, 1077-1082.

Charlet, K., Baley, C., Morvan, C., Jernot, J.P., Gomina, M., Bréard, J., 2007. Characteristics of Hermès flax fibres as a function of their location in the stem and properties of the derived unidirectional composites. Compos. Part A Appl. Sci. Manuf. 38, 1912-1921.

Dhakal, H.N., Zhang, Z.Y., Richardson, M.O.W., 2007. Effect of water absorption on the mechanical properties of hemp fibre reinforced unsaturated polyester composites. Compos. Sci. Technol. 67, 1674-1683.

Di Giuseppe, E., Castellani, R., Dobosz, S., Malvestio, J., Berzin, F., Beaugrand, J., Delisée, C., Vergnes, B., Budtova, T., 2016. Reliability evaluation of automated analysis, 2D scanner, and micro-tomography methods for measuring fiber dimensions in polymer-lignocellulosic fiber composites. Compos. Part A Appl. Sci. Manuf. 90, 320-329.

Faruk, O., Bledzki, A.K., Fink, H.-P., Sain, M., 2012. Biocomposites reinforced with natural fibers: 2000-2010. Prog. Polym. Sci. 37, 1552-1596.

Haag, K., Padovani, J., Fita, S., Trouvé, J.P., Pineau, C., Hawkins, S., De Jong, H., Deyholos, M.K., Chabbert, B., Müssig, J., Beaugrand, J., 2017. Influence of flax fibre variety and year-to-year variability on composite properties. Ind. Crops Prod. 98, 1-9.

Hamdi, S.E., Delisée, C., Malvestio, J., Da Silva, N., Le Duc, A., Beaugrand, J., 2015. $\mathrm{X}$-ray computed microtomography and $2 \mathrm{D}$ image analysis for morphological characterization of short lignocellulosic fibers raw materials: A benchmark survey. Compos. Part A Appl. Sci. Manuf. 76, 1-9.

Ismail, S.O., Dhakal, H.N., Dimla, E., Beaugrand, J., Popov, I., 2016. Effects of drilling parameters and aspect ratios on delamination and surface roughness of lignocellulosic HFRP composite laminates. J. Appl. Polym. Sci. 133, 1-8.

Joshi, S. V, Drzal, L.T., Mohanty, A.K., Arora, S., 2004. Are natural fiber composites 
environmentally superior to glass fiber reinforced composites? Compos. Part A Appl. Sci. Manuf. 35, 371-376.

Mohanty, A.K., Misra, M., Hinrichsen, G., 2000. Biofibres, biodegradable polymers and biocomposites: An overview. Macromol. Mater. Eng. 276-277, 1-24.

Nasser, R., Salem, M., Hiziroglu, S., Al-Mefarrej, H., Mohareb, A., Alam, M., Aref, I., 2016. Chemical Analysis of Different Parts of Date Palm (Phoenix dactylifera L.) Using Ultimate, Proximate and Thermo-Gravimetric Techniques for Energy Production. Energies 9, 374.

Paul, V., Kanny, K., Redhi, G.G., 2015. Mechanical, thermal and morphological properties of a bio-based composite derived from banana plant source. Compos. Part A Appl. Sci. Manuf. 68, 90-100.

Pickering, K.L., Efendy, M.G.A., Le, T.M., 2016. A review of recent developments in natural fibre composites and their mechanical performance. Compos. Part A Appl. Sci. Manuf. 83, 98-112.

Shah, D.U., 2014. Natural fibre composites: Comprehensive Ashby-type materials selection charts. Mater. Des. 62, 21-31.

Stamboulis, A., Baillie, C.A., Peijs, T., 2001. Effects of environmental conditions on mechanical and physical properties of flax fibers. Compos. Part A Appl. Sci. Manuf. 32, 1105-1115.

Summerscales, J., Dissanayake, N.P.J., Virk, A.S., Hall, W., 2010. A review of bast fibres and their composites. Part 1 - Fibres as reinforcements. Compos. Part A Appl. Sci. Manuf. 41, 1329-1335.

Vergnes, B., Della Valle, G., Delamare, L., 1998. A global computer software for polymer flows in corotating twin screw extruders, Polym. Eng. Sci., 38, 17811792.

\section{Figure captions:}

Fig. 1. Schematic representation of sequence and processing steps of Date Palm Tree grown in Kingdom of Saudi Arabia and fibre extracted from leaf sheath a) Date Palm Tree grown in Kingdom of Saudi Arabia and b) fibre (fibrillum) extracted from leaf sheath. c) palm fibers lot chopped prior to twin screw extrusion; d) palm fibres from c) extruded at $100 \mathrm{rpm}$ after extraction of the PCL matrix, e) palm fibres from c) extruded at $400 \mathrm{rpm}$ after extraction of the PCL matrix. The scale bar $=1 \mathrm{~cm}$. Lower part: box plots corresponding to the three images.

Fig. 2. SEM images of date palm fibre used in this study showing pores morphology: (a) longitudinal section at lower magnification x 150; (b) at higher magnification $\mathrm{x} 500$

Fig. 3. Ashby chart presenting strength versus modulus of our date palm composites (red) in an Ashby chart, comparing with other bast fibre composites. Adapted from (Shah, 2014). Acronyms are: IM injection moulded, CM compression moulded, RTM resin transfer moulded, UD unidirectional, TP thermoplastic, TS thermoset 
463 Fig. 4. Evolution of SME at $3.5 \mathrm{~kg} / \mathrm{h}(\mathrm{O}: 100 \mathrm{rpm} ; \bullet: 400 \mathrm{rpm})$ along the screw 464 profile and comparison with experimental SME measured at the die exit (restrictive 465 zones are in grey)

466 Fig. 5. Schematic of low velocity impact test set up

467 Fig. 6. (a) Force versus displacement, (b) Load versus time and (c) Work versus 468 time traces of palm/PCL biocomposites.

$469 \quad$ Fig. 7. (a) Force versus displacement, (b) Load versus time and (c) Work versus 470 time traces of hemp PCL for comparison purpose.

471 Fig. 8. Damage pattern of Palm/PCL specimens impacted at 25 Joules (a) front 472 face damage and (b) rear face damage.

473 Fig. 9. Damage pattern of Palm/PCL specimens impacted at 50 Joules (a) front 474 face damage and (b) rear face damage

475 Fig. 10. SEM images of Palm/PCL after impact test at 25J, 1: delamination and 476 debonding, 2: matrix bending, 3: fibres breakage, 4: fibre pull out, 5: pull out fibre 477 side

479 Fig. 11. SEM images of Palm/PCL after impact test at 50J, 1: delamination, 2: 480 matrix breaking, 3: fibres breakage 


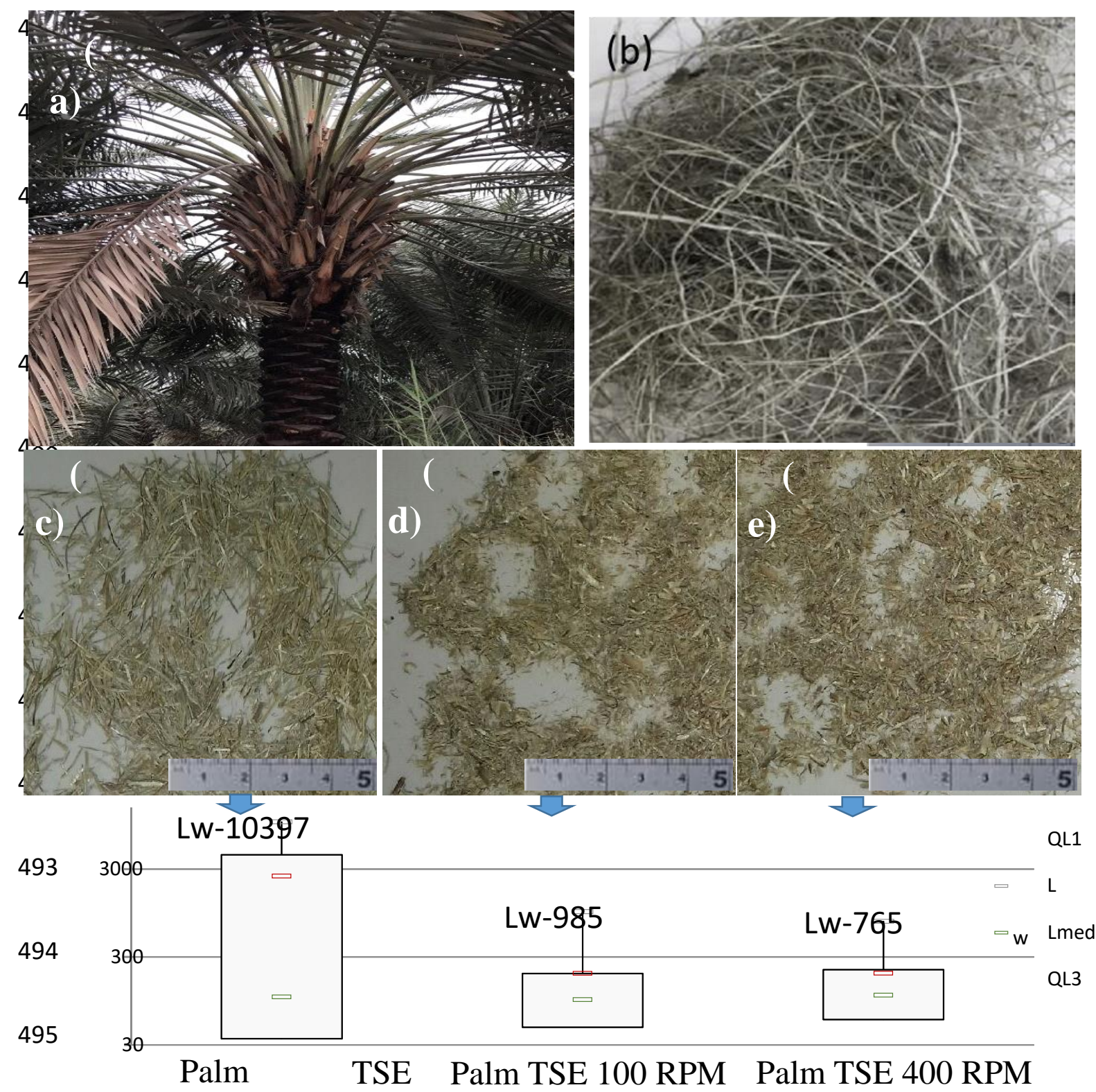

496

497

498

499

500

501

502 
503 Fig. 1. Schematic representation of sequence and processing steps of Date Palm 504 Tree grown in Kingdom of Saudi Arabia and fibre extracted from leaf sheath a) Date 505 Palm Tree grown in Kingdom of Saudi Arabia and b) fibre (fibrillum) extracted from 506 leaf sheath. c) palm fibers lot chopped prior to twin screw extrusion; d) palm fibres 507 from c) extruded at $100 \mathrm{rpm}$ after extraction of the PCL matrix, e) palm fibres from c) 508 extruded at $400 \mathrm{rpm}$ after extraction of the PCL matrix. The scale bar $=1 \mathrm{~cm}$. Lower 509 part: box plots corresponding to the three images.

510
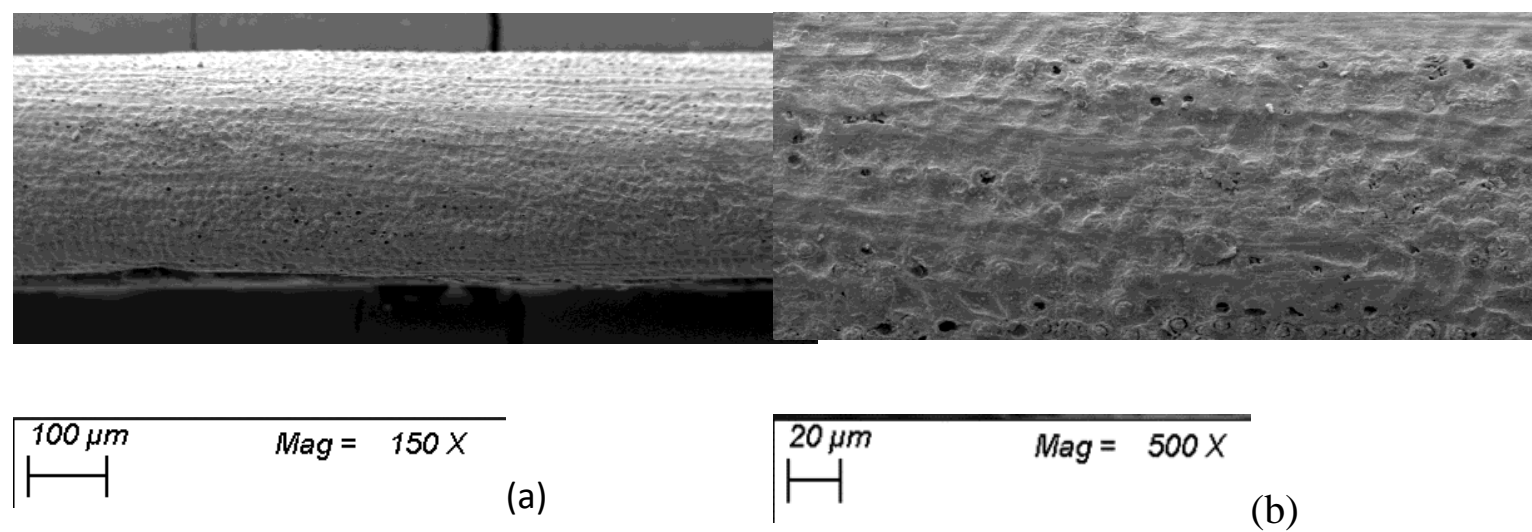

(b)

Fig. 2. SEM images of date palm fibre used in this study showing pores morphology: (a) longitudinal section at lower magnification x 150; (b) at higher magnification x 500 . 


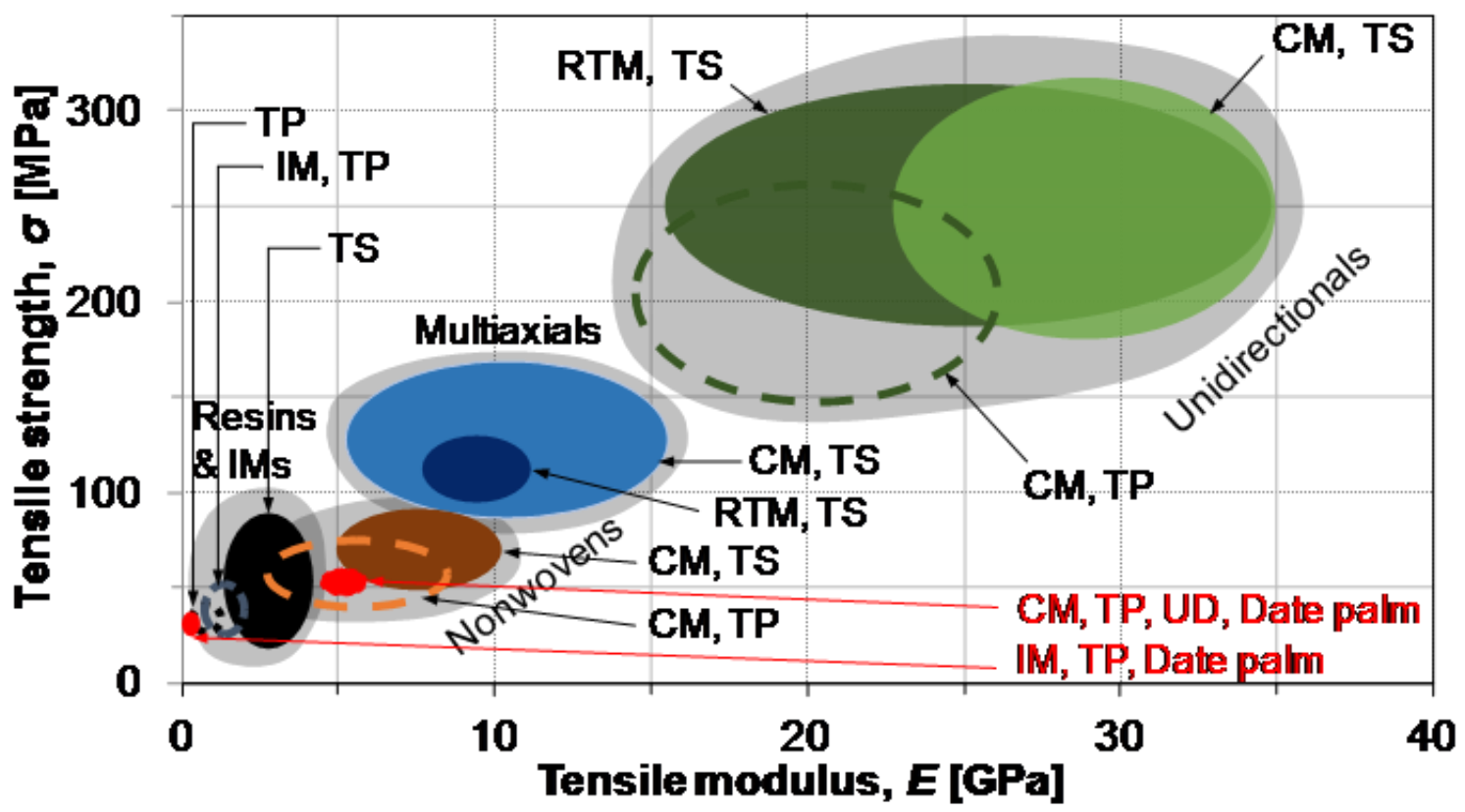

Fig. 3. Ashby's chart presenting strength versus modulus of our date palm composites (red) in an Ashby chart, comparing with other bast fibre composites.The strength versus modulus in as Ashby's chart (adapted from REF: Shah, 2014). Acronyms are: IM injection moulded, CM compression moulded, RTM resin transfer moulded, UD unidirectional, TP thermoplastic, TS thermoset. 


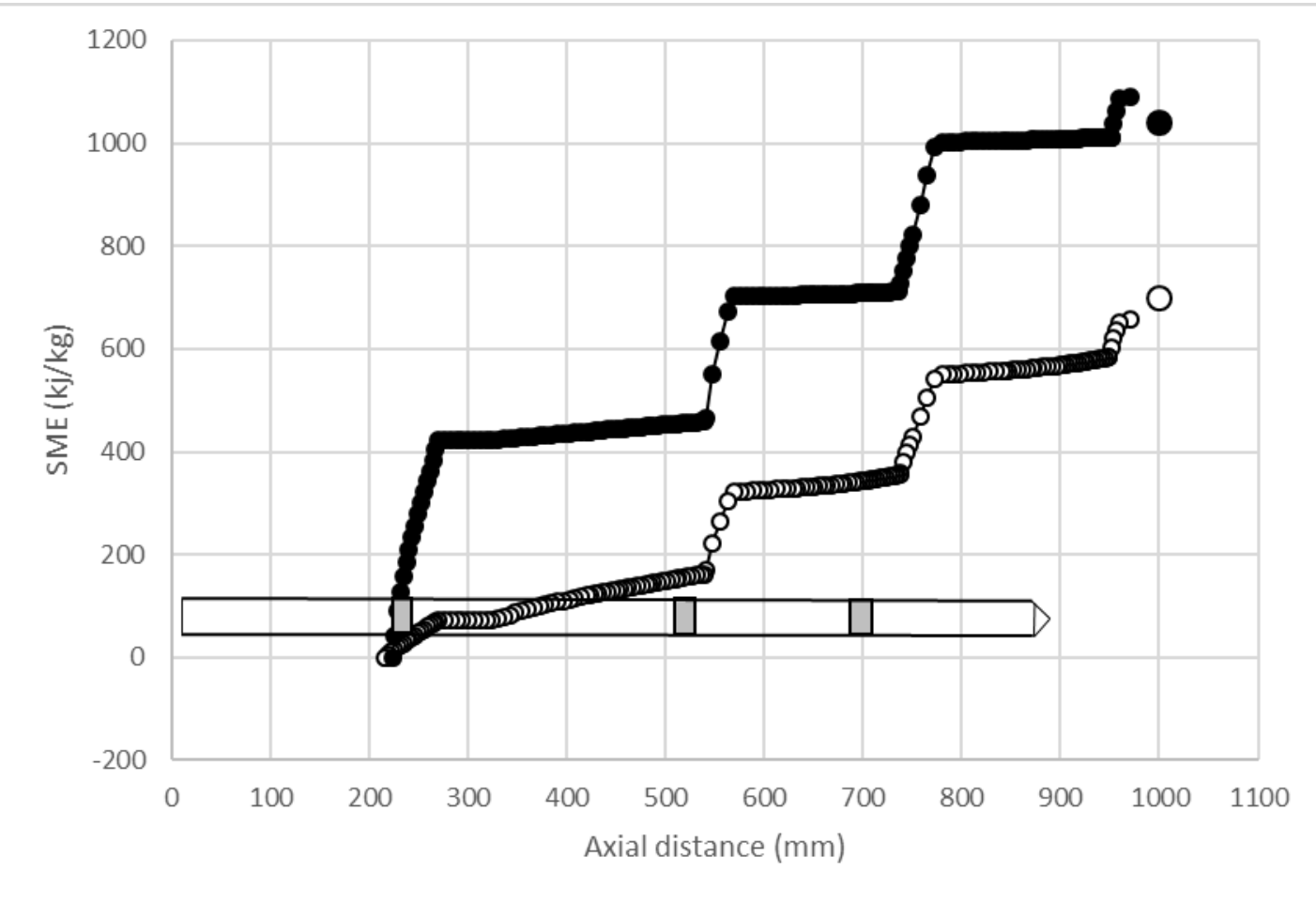

518 Fig. 4. Evolution of SME at $3.5 \mathrm{~kg} / \mathrm{h}(\mathrm{O}: 100 \mathrm{rpm} ; \bullet: 400 \mathrm{rpm})$ along the screw

519 profile and comparison with experimental SME measured at the die exit (restrictive 520 zones are in grey). 


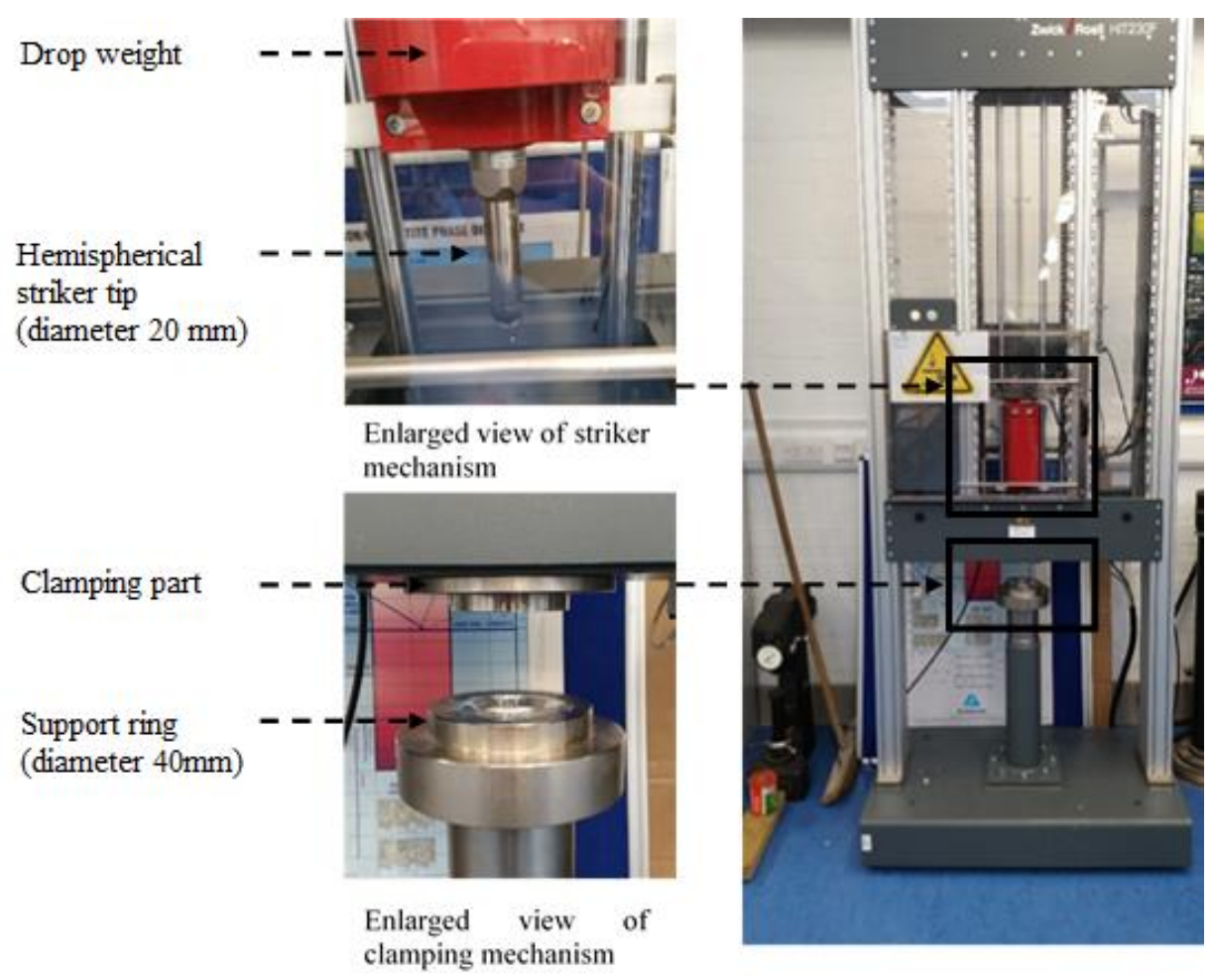

Fig. 5. Schematic of low velocity impact test set up.

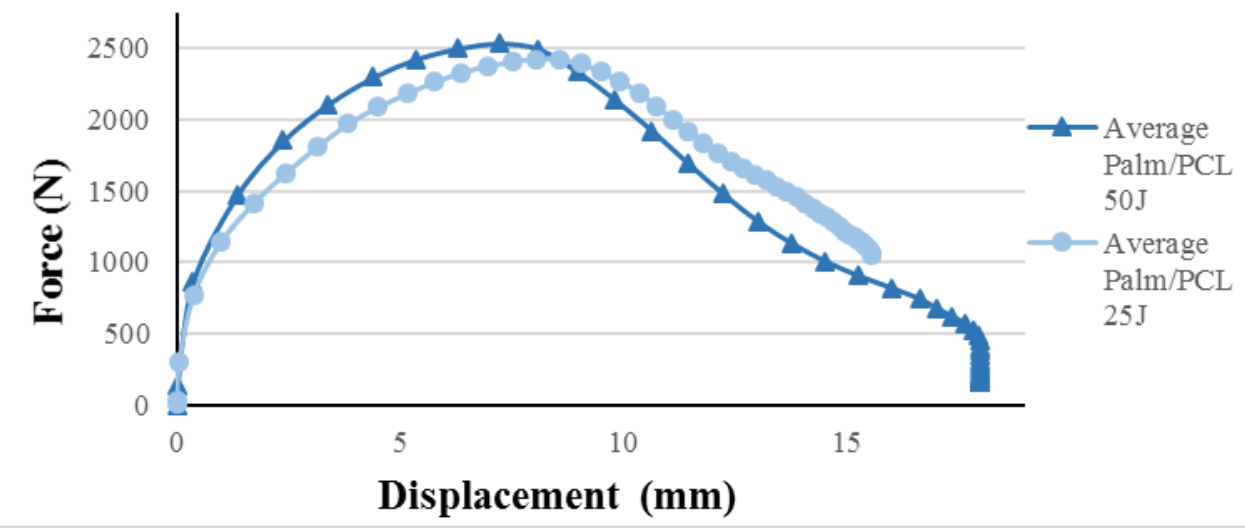

(a) 


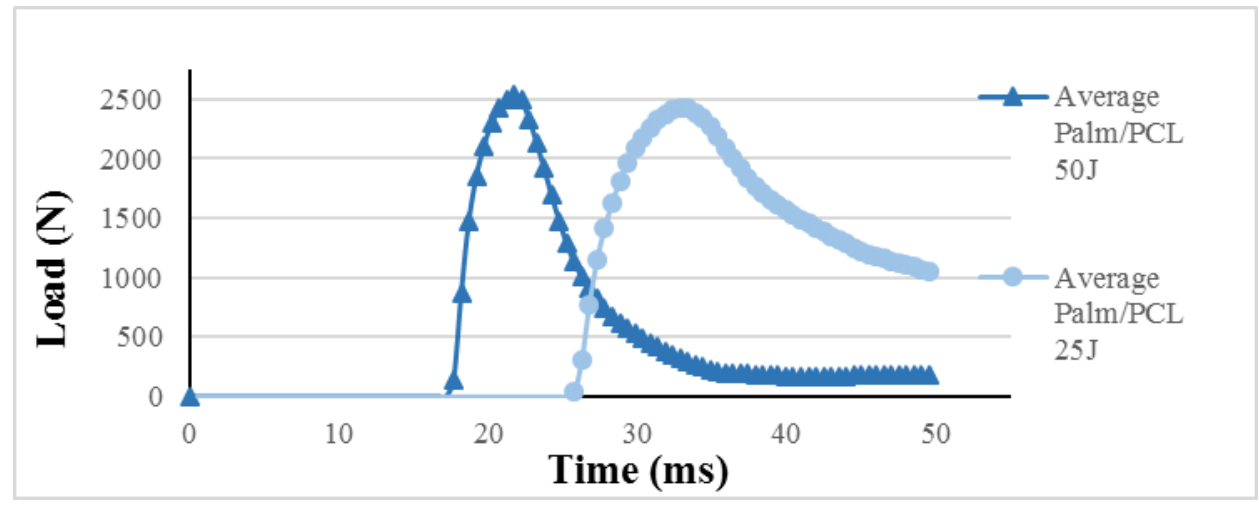

(b)

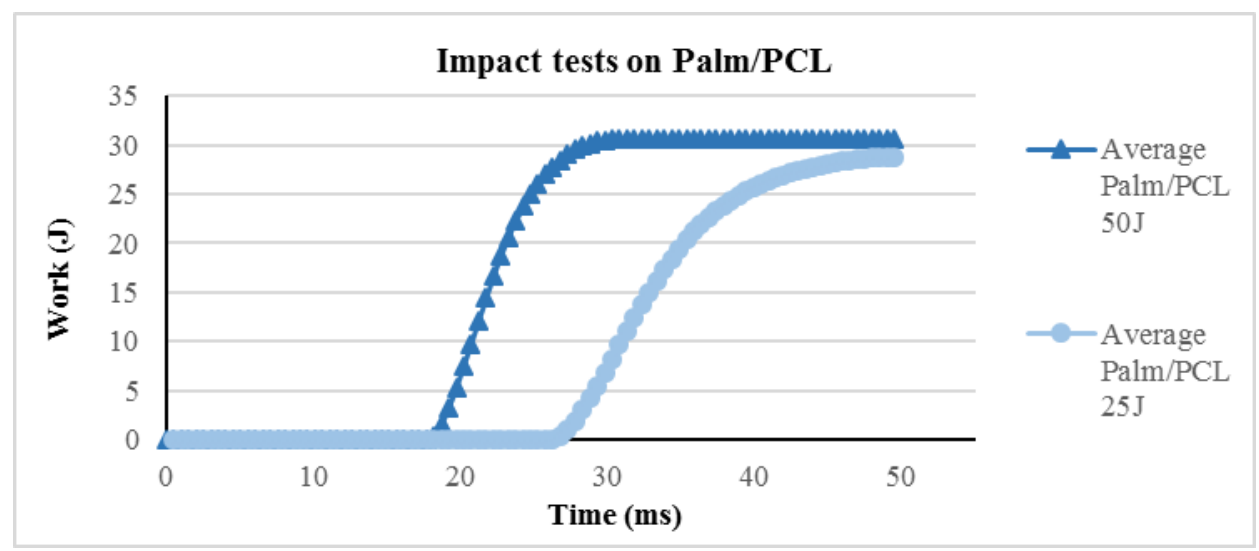

(c)

Fig. 6. (a) Force versus displacement, (b) Load versus time and (c) Work versus time traces of palm/PCL biocomposites.

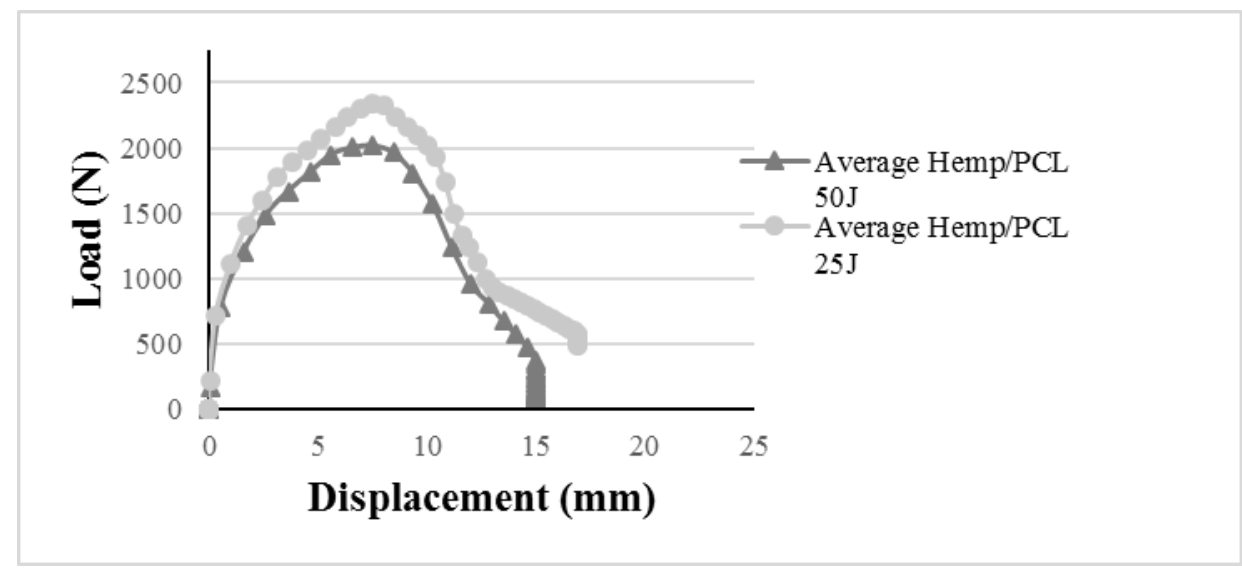

(a) 


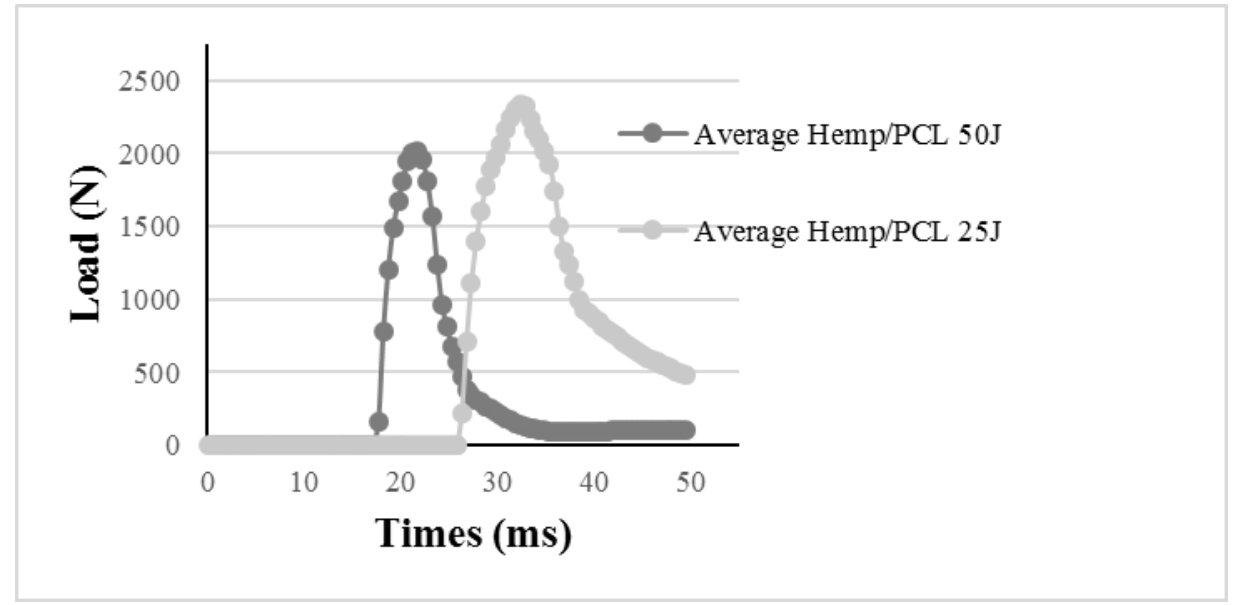

(b)

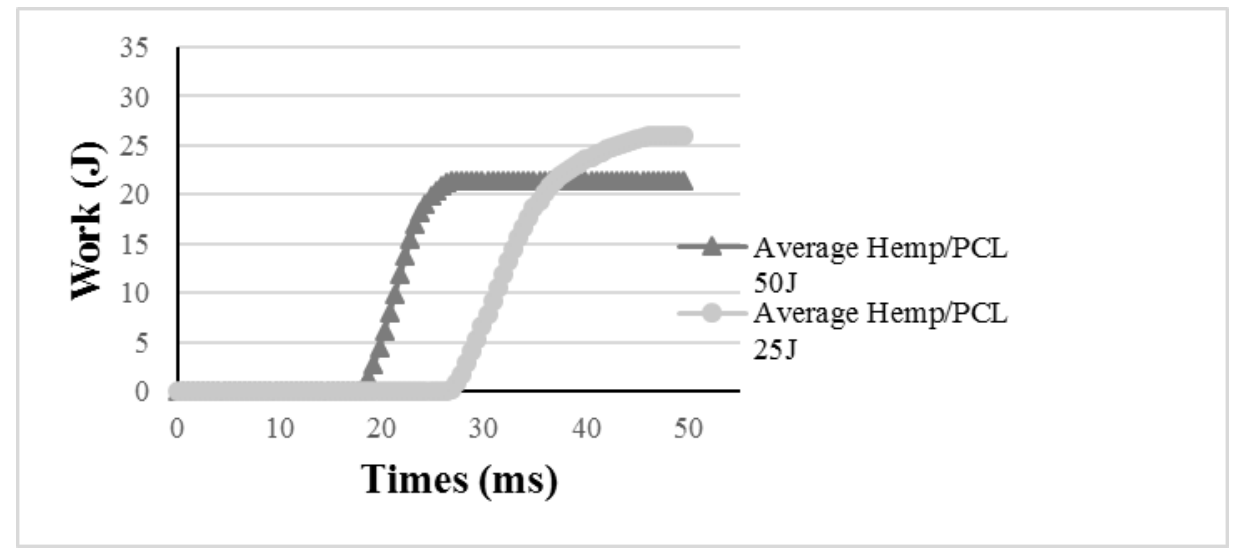

(c)

Fig. 7. (a) Force versus displacement, (b) Load versus time and (c) Work versus time traces of hemp PCL for comparison purpose.
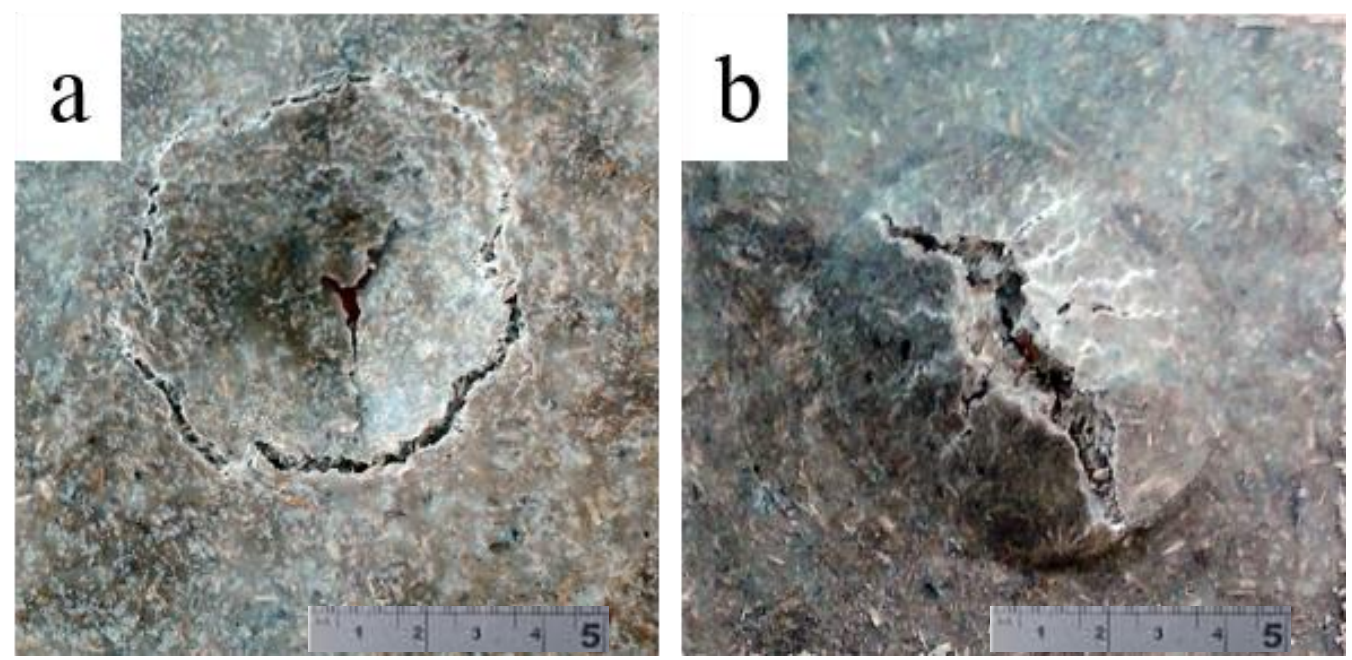
Fig. 8. Damage pattern of Palm/PCL specimens impacted at 25 Joules (a) front face damage and (b) rear face damage.
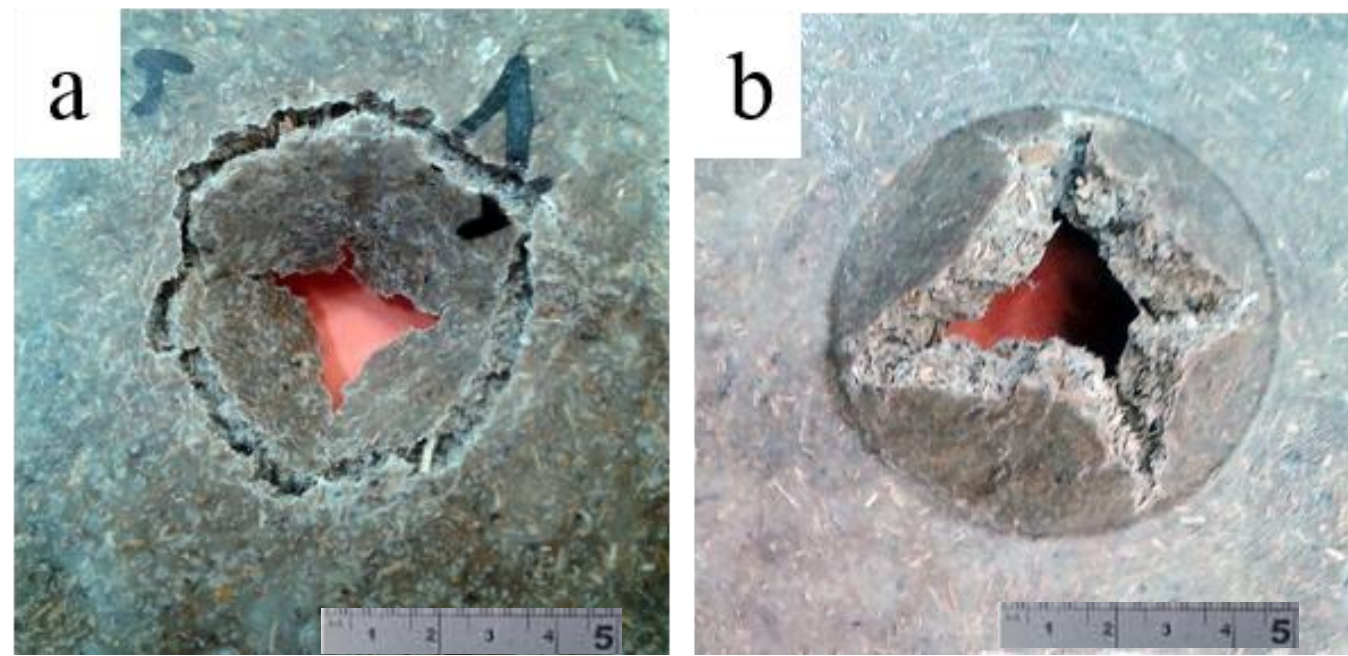

Fig. 9. Damage pattern of Palm/PCL specimens impacted at 50 Joules (a) front face damage and (b) rear face damage.
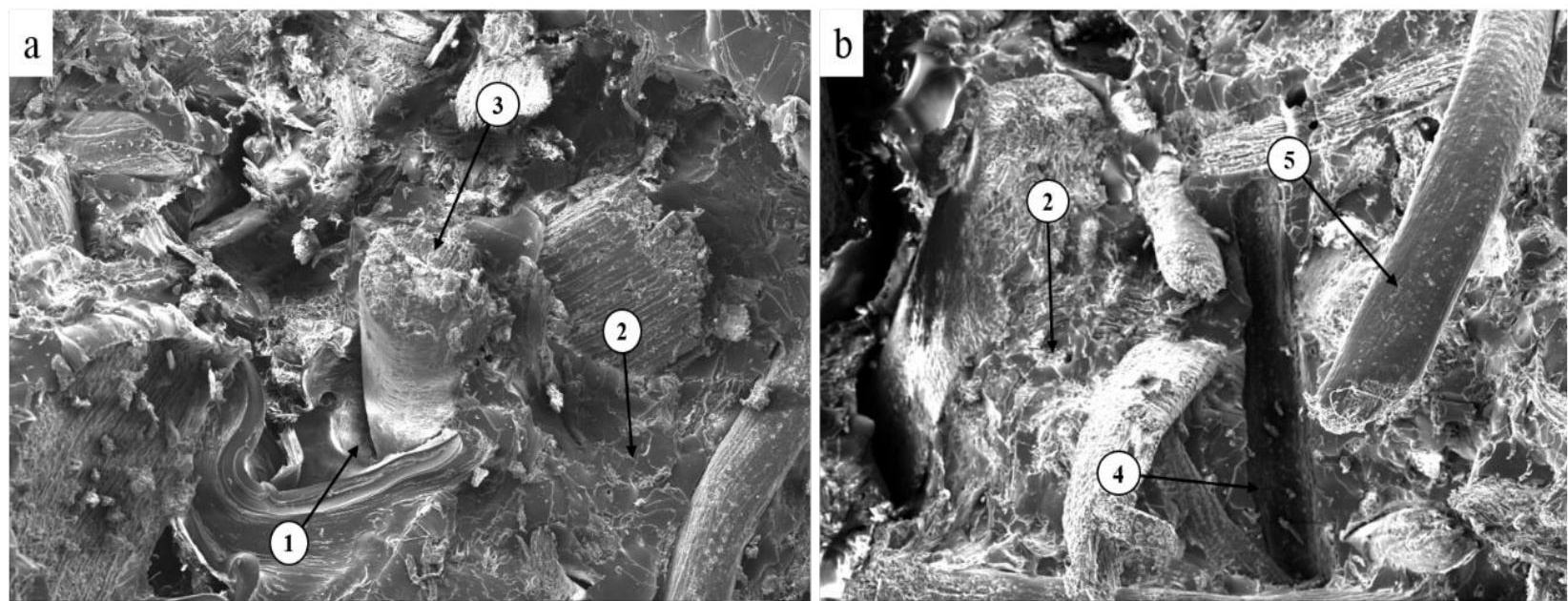

$300 \mu \mathrm{m}$ Mag $=150 x$

$200 \mu m \quad M a g=150 X$

Fig. 10. SEM images of Palm/PCL after impact test at 25J, 1: delamination and debonding, 2 : matrix bending, 3: fibres breakage, 4: fibre pull out, 5: pull out fibre side. 
528

529 

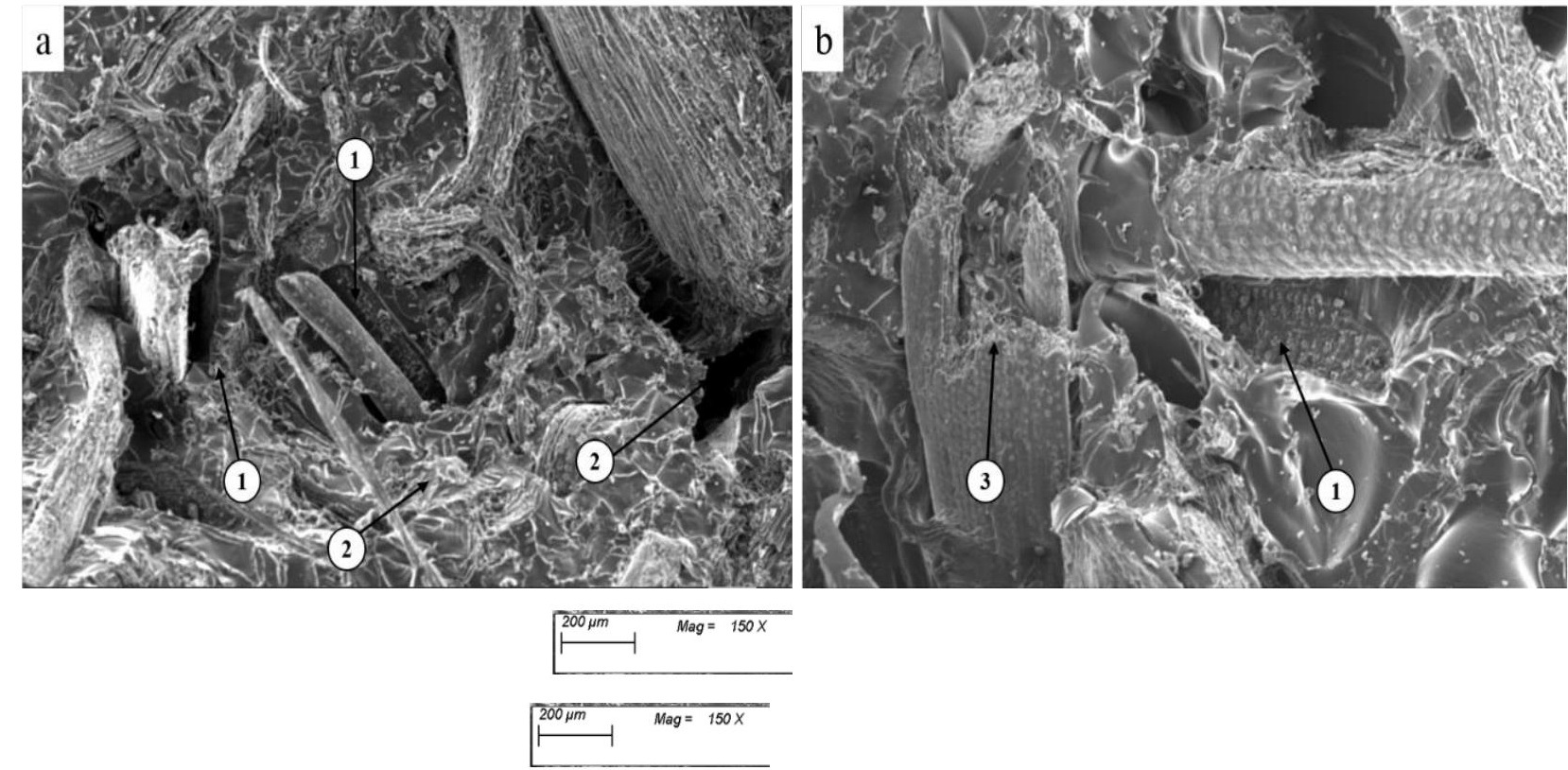

Fig. 11. SEM pictures of Palm/PCL after impact test at 50J, 1: delamination, 2: matrix breaking, 3: fibres breakage.

Table captions:

Table 1: Comparative physical and mechanical properties of date palm fibre

533 (bundles) with commonly used bast fibres (Dhakal et al., 2007; Mohanty et al., 2000;

534 Pickering et al., 2016).

\begin{tabular}{lcccc}
\hline Fibre types & $\begin{array}{c}\text { Density } \\
\left(\mathrm{g} / \mathrm{cm}^{3}\right)\end{array}$ & $\begin{array}{c}\text { Tensile } \\
\text { strength at } \\
\text { break (MPa) }\end{array}$ & $\begin{array}{c}\text { Tensile } \\
\text { modulus }(\mathrm{GPa})\end{array}$ & $\begin{array}{c}\text { Elongation at } \\
\text { break } \\
(\%)\end{array}$ \\
\hline Date palm & 0.92 & $170-275$ & $5-12$ & $5-10$ \\
\hline Hemp & 1.14 & $550-1110$ & $58-70$ & 1.6 \\
\hline Flax & 1.50 & $345-1100$ & 27.6 & $2.7-3.2$ \\
\hline Jute & $1.3-1.45$ & $393-773$ & $13-26.5$ & $1.16-1.5$
\end{tabular}

537 Table 2: Effects of palm fibre reinforcement on tensile properties of different 538 palm/PCL biocomposites. 


\begin{tabular}{cccc}
\hline $\begin{array}{c}\text { Specimen } \\
\text { types }\end{array}$ & $\begin{array}{c}\text { Tensile } \\
\text { strength at } \\
\text { break (MPa) }\end{array}$ & $\begin{array}{c}\text { Tensile } \\
\text { modulus (MPa) }\end{array}$ & $\begin{array}{c}\text { Tensile strain } \\
(\%)\end{array}$ \\
\hline PCL neat & 19.00 & 140.00 & 418.00 \\
& $( \pm 1.70)$ & $( \pm 24.0)$ & $( \pm 60.0)$ \\
\hline PCL Palm 20 & 24.00 & 284.00 & 21.00 \\
wt.\% 100 RPM & $( \pm 2.90)$ & $( \pm 15.20)$ & $( \pm 4.0)$ \\
\hline PCL Palm 20 & 25.00 & 279.50 & 24.00 \\
wt.\% 400 RPM & $( \pm 0.70)$ & $( \pm 14.50)$ & $( \pm 3.0)$ \\
& & & \\
\hline
\end{tabular}

539

540

$541 \quad$ Highlights:

542

- The focus of the study was valorisation of waste agriculture biomass leaf sheath date palm fibre through the development of composite laminates.

- Fully biodegradable date palm/PCL based biocomposites developed and their

545 damage mechanisms under LVI investigated.

- Important mechanical properties were investigated and compared against hemp PCL biocomposites.

548 - The developed biocomposites have high potential to be utilized for lightweight $549 \quad$ engineering applications.

550 